\title{
ARTICLE OPEN \\ Studying the burden of community-acquired pneumonia in adults aged $\geqslant 50$ years in primary health care: an observational study in rural Crete, Greece
}

\author{
Antonios Bertsias ${ }^{1}$, loanna G Tsiligianni ${ }^{1}$, George Duijker ${ }^{1}$, Nikolaos Siafakas ${ }^{2}$ and Christos Lionis ${ }^{1}$ on behalf of the Cretan CAP Research \\ Group
}

BACKGROUND: Community-acquired pneumonia (CAP) is a potentially life-threatening condition that often requires hospitalisation particularly in the elderly population or in patients with comorbidities.

AIMS: The aims of this study were to estimate the CAP frequency and severity in a well-defined primary healthcare setting in rural Crete, to record patient characteristics, their immunisation status and to estimate hospitalisation frequency and determinants. METHODS: An observational study was designed and implemented in a rural setting within the prefecture of Heraklion in the island of Crete, Greece. Eligible patients were those aged 50 years or above, presenting with CAP based on signs and symptoms and positive X-ray findings.

RESULTS: A total of 124 CAP cases were recorded, 40 of which (32.3\%) were hospitalised. The age-standardised CAP incidence was estimated to be 236.7 cases per 100,000 persons aged $\geqslant 50$ years. Forty-three patients (35.2\%) were vaccinated against pneumococcus. The most frequent chronic illnesses were heart disease (64.5\%), chronic obstructive pulmonary disease (32.5\%), and type 2 diabetes (21\%). Hospitalisation determinants included advanced age ( $\geqslant 74$ years, Odds ratio (OR) $7.13 ; P$ value $=0.001 ; 95 \%$ confidence interval $(\mathrm{Cl}), 2.23-22.79)$, obesity (OR 3.36, $P=0.037 ; 95 \% \mathrm{Cl}, 1.08-10.52)$, $\geqslant 40$ pack-years of smoking (OR 3.82, $P$ value $=0.040 ; 95 \% \mathrm{Cl}, 1.07-18.42)$, presence of multimorbidity (OR 5.77, $P$ value $=0.003 ; 95 \% \mathrm{Cl}, 1.81-18.42)$ and pneumococcal vaccination (OR $0.29, P$ value $=0.041 ; 95 \% \mathrm{Cl}, 0.09-0.95$ ).

CONCLUSIONS: This study highlighted patient characteristics and aspects of CAP epidemiology in the context of a rural primary care setting in southern Europe where limited data have been published until now.

npj Primary Care Respiratory Medicine (2014) 24, 14017; doi:10.1038/npjpcrm.2014.17; published online 26 June 2014

\section{INTRODUCTION}

Community-acquired pneumonia (CAP) is one of the most common infectious diseases worldwide that is associated with increased mortality in older adults and in individuals with chronic illnesses. ${ }^{1}$ CAP often develops outside the hospital setting and can be caused by a variety of pathogens, by both bacteria and viruses. $^{2,3}$ In the United States, CAP is the leading cause of death caused by infectious diseases. ${ }^{4}$ Its severity and treatment can vary, and a considerable proportion of patients often require hospitalisation. The predominant pathogen in CAP is Streptococcus pneumoniae (S. pneumoniae), which accounts for a significant part of all cases of bacteraemic pneumonia. S. pneumoniae is also responsible for about $50 \%$ of all cases requiring admission to the hospital. ${ }^{5}$ Owing to the high antibiotic-resistant strains of S. pneumoniae, it is important to detect, diagnose, assess the severity and treat pneumonia in daily clinical practice. ${ }^{1,6}$

Certain studies have indicated a varying incidence ranging from 1.6 to 9 cases per 1,000 persons in the general adult population. ${ }^{5,7-10}$ These studies have also highlighted inconsistent hospitalisation rates owing to CAP ranging from 8 to 51\%. CAP mortality varies significantly between hospitalised patients and outpatients. Studies have reported mortality from a low $5 \%$ to a high $15 \%$ among hospitalised patients, whereas this figure is less than $1 \%$ for outpatients. ${ }^{11,12}$ The financial burden of the disease worldwide is estimated to be $\$ 4.8$ billion for patients aged $\geqslant 65$ years and $\$ 3.6$ billion for patients aged $<65$ years. ${ }^{13}$ In addition to this, the total cost of inpatient management could be 20 times higher than the total cost for outpatient management. ${ }^{14}$ There is much interest about the prevention of CAP and much discussion in the literature has been dedicated to that subject. Vaccines against S. pneumoniae are available worldwide and are utilised by health-care services. ${ }^{15}$

In their daily practice, general practitioners frequently encounter patients presenting with a vast variety of medical conditions. Sometimes decisions by general practitioners to refer their patient to a specialist are made within a very narrow consultation time, within a duration of $6-12 \mathrm{~min}^{16}$ In addition, respiratory tract infections are the most common reason for consultation in primary health care $(\mathrm{PHC})$ resulting in $15 \%$ of the total primary care consultations. ${ }^{17}$ Under such circumstances and given that CAP is a potentially life-threatening condition, the identification of CAP patients in need of immediate treatment seems to be quite imperative. ${ }^{18}$ For all those reasons, diagnosis of CAP in outpatient settings and in $\mathrm{PHC}$ remains a challenge owing to the variety of signs and symptoms that can be presented. ${ }^{19}$ According to the British Thoracic Society guidelines summary for PHC, CAP has

${ }^{1}$ Clinic of Social and Family Medicine, Faculty of Medicine, University of Crete, Heraklion, Greece and ${ }^{2}$ Department of Thoracic Medicine, Faculty of Medicine, University of Crete, Heraklion, Greece.

Correspondence: C Lionis (lionis@galinos.med.uoc.gr)

Received 4 December 2013; revised 14 March 2014; accepted 29 April 2014 
been defined as symptoms of an acute lower respiratory tract illness, new focal chest signs on examination, evidence of systemic illness, no other explanation for the illness, and a clinical decision that should be treated as CAP. ${ }^{18}$

In rural Greece, the management of CAP in the community is primarily performed by general practitioners serving remote and rural practices or health-care centres. However, as a patient gatekeeping system is lacking in the country, patients are able to visit public hospitals or even private clinics whenever they choose. As regards CAP epidemiology, there is in general a paucity of data in the country. There are still questions about the incidence rates of CAP in PHC, the vaccination coverage of patients affected by CAP and the underlying conditions that could favour this infection. It is unknown as to what extent the changing human and social environment on rural Crete has an impact on CAP morbidity and its hospitalisation rates. In addition, although certain empirical studies carried out at a primary care level in Crete indicated a poor vaccination rate against pneumococcus in people with chronic diseases, it remained unclear as to what extent patients affected with CAP were vaccinated or not.

\section{Aims and objectives of the study}

To that purpose, an observational study was designed and implemented in rural Crete to gain insights into the burden of CAP. This study aimed to assess the CAP incidence among residents of a well-defined rural area who visited the selected health-care services (both primary and hospital), the frequency of the underlying chronic conditions of CAP patients, smoking and alcohol consumption and their level of vaccination coverage against pneumococcus and influenza. The study's objectives were to assess the severity of CAP cases in the community, to estimate the hospitalisation rates due to CAP and identify the hospitalisation determinants to assess the possible preventive role of pneumococcal vaccination in adults. The results of this study are expected to have an impact on both continuous professional education and health policy.

\section{MATERIALS AND METHODS}

\section{Setting}

A cross-sectional, multicentre study was designed and implemented in a well-defined rural setting in the prefecture of the Heraklion district in the island of Crete, Greece. The duration of the observation period was 1 year (from 15 March 2011 to 15 March 2012). The permanent residents of rural areas in the Prefecture of Heraklion served as the target population. The selected setting included all six rural public PHC capacities of the district and namely the Health Centers of Ano Viannos, Arkalochori, Kastelli, Agia Varvara, Moires and Charakas and both pulmonary hospital clinics located in the Heraklion city (namely Venizeleio \& PAGNI hospitals). The two pulmonary clinics had access to the respective hospitals' emergency care units. The selected setting covered all possible public health facilities where the rural population could have access to.

\section{Population and inclusion-exclusion criteria}

Eligible patients were those aged 50 years or older, permanent residents of the rural area in the prefecture of the Heraklion district $(n=45,300)$ who visited one of the six PHC capacities in the rural areas of the Heraklion prefecture, or one of the two public pulmonary hospital clinics, and presented signs and symptoms of a lower respiratory infection with an X-ray confirming CAP. Previously hospitalised patients (for whatever reason other than (AP) discharged less than 14 days from hospital who presented signs and symptoms of pneumonia were intended to be excluded from the study in order to avoid cases of nosocomial infection. However, there were no such cases in our study.

\section{Measurements and data collection}

Structured and pretested baseline and follow-up questionnaires were used in order to elicit information on patients' characteristics. The baseline questionnaire included questions about the participants' sociodemographic status (age, gender, educational and marital status), their socio-economic status (employment status, number of housemates and those aged 5 years or less, smoking and alcohol consumption), and immunisation status (vaccination against pneumococcus and influenza). Information regarding chronic illnesses and prescribed medication were obtained from the available patients' medical records. Baseline questionnaires also included information on symptoms and clinical signs of the disease (temperature, confusion, chest pain, respiratory auscultation sounds, lung-percussion, dyspnoea, chest pain, and sleep hyperhidrosis). Follow-up questionnaires were used for hospitalised patients and outpatients. These questionnaires included information regarding impatient and outpatient disease management (referral to the hospital and outpatients' number of visits to their general practitioners, number of days in hospital, haematological and laboratory diagnostic tests, referral to the intensive care unit, re-hospitalisation, and medications). Clinical measurements recorded in both questionnaires included systolic and diastolic blood pressure ( measured in $\mathrm{mm} \mathrm{Hg}$ ), respiratory rate (measured in breaths per minute-b.p.m.) and $\mathrm{O}_{2}$ saturation (\%). Haemoglobin, arterial oxygen, and white blood cell count were obtained from blood samples. Questionnaires were collected, checked for completeness and consistency and their data were stored in an electronic database.

\section{Definitions}

CAP was defined as a respiratory infection associated with signs and symptoms of an acute lower respiratory infection according to the British Thoracic Society confirmed with a lung infiltrate in the chest X-ray. ${ }^{18}$ The CRB- $65^{20,21}$ (C: confusion, R: respiratory rate, B: blood pressure, 65 years of age and older) score was computed for each patient with complete data in order to provide information regarding the severity of the disease. Patients were classified as obese when body mass index (BMI) $>30 \mathrm{~kg} / \mathrm{m}^{2}$. Smokers were classified as never smokers, light smokers or moderate smokers (1-39 pack-years of smoking), and heavy smokers (40 or more pack-years of smoking). Multimorbidity was defined as the presence of two or more chronic illnesses.

\section{Bioethics}

This study was designed by a research team at the Clinic of Social and Family Medicine and was approved by the Commission of Bioethics of the University Hospital of Heraklion (protocol number: 13541, 20.11.2010). All patients were enrolled after being informed about the study and provided a written consent.

\section{Statistical analysis}

Univariate analysis of continuous variables (age and BMI) was performed using the nonparametric Mann-Whitney test. Univariate analysis of categorical variables was performed using the $x^{2}$-test of independence, as well as Fisher's exact test. Age was dichotomised at median into two categories ( $\geqslant 74$ years, $<74$ years). Patients were also dichotomised into two categories according to their BMI (obese: those with a BMI $>30 \mathrm{~kg} / \mathrm{m}^{2}$, and nonobese: those with a BMI $\leqslant 30 \mathrm{~kg} / \mathrm{m}^{2}$ ). From the data collected from questionnaires, the number of pack-years was computed for each patient. After quartile analysis, the number of pack-years of smoking was divided into three categories: 0 pack-years, nonsmokers; 1-39 pack-years of smoking, low and moderate amount of smoking; $\geqslant 40$ packyears of smoking, heavy smokers. Unconditional multivariate logistic regression with the dependent variable being the patient hospitalisation (yes/no) was performed in order to identify the determinants for hospitalisation due to CAP. The independent variables used in the regression model were age category $(\geqslant 74 /<74$ years), presence of obesity (yes/no), pack-years of smoking category (0 pack-years/(1-39) pack-years/ $\geqslant 40$ pack-years), presence of multimorbidity (yes/no), and pneumococcal vaccination (yes/no). The Hosmer and Lemeshow test was used to assess the fit of the model. Inpatients were also dichotomised at median according to the level of arterial oxygen in their blood $(\leqslant 58.8$ and $>58.8 \mathrm{mg} / \mathrm{dl}$ ). The level of statistical significance was set to $5 \%$, and the statistical software package used was SPSS Statistics version 19 (IBM, Chicago, IL, USA). 


\section{RESULTS}

CAP frequency, general information on patient demographics, smoking, and socio-economic and vaccination status

A total of 124 CAP cases were registered, 64 were men $(51.6 \%)$ and 60 were women $(48.2 \%)$. The crude incidence of CAP was estimated to be 273.5 cases per 100,000 persons aged 50 years or older. On the basis of the European standard population, the agestandardised incidence of CAP was estimated to be 236.7 cases per 100,000 persons aged 50 years or older.

Forty patients (32.3\%) were hospitalised, whereas the remaining 84 cases were treated as outpatients. Two out of the 40 hospitalised patients died during hospitalisation and one patient was re-admitted owing to CAP 3 months after the initial discharge. Demographic, socio-economical, and anthropometric characteristics are depicted in Table 1. Significant differences between men and women were observed only with regard to smoking and alcohol consumption. Forty-five percent of patients were current/ former smokers, almost one-third of patients were obese (31.9\%) and although the majority (61.5\%) were vaccinated against influenza only a minority were vaccinated against pneumococcus with the 23 -valent polysaccharide vaccine $(35.2 \%)$. Most patients were married $(71.8 \%)$, retired or housewives $(86.1 \%)$, and with no or only primary education (87.5\%). The median reported number of housemates was two. Only two participants reported living together with children aged less than 5 years. The median reported number of rooms in the participants' household was four.

\section{Underlying morbidity}

Heart disease was the most common chronic illness (64.5\%), followed by chronic obstructive pulmonary disease (COPD) (32.5\%) and type 2 diabetes (21.0\%). A significant proportion of patients suffered from multimorbidity (43\%). Significant differences in frequencies of chronic illnesses between men and women were reported for COPD, which was more predominant in men (odds ratio (OR) 3.80, 95\% confidence interval $(\mathrm{Cl}), 1.67-8.60$, $P<0.001$ ), and asthma, which was more evident in women (male to female OR $0.12,95 \% \mathrm{Cl}, 0.01-0.99, P=0.022$ ). Further details are shown in Table 2.
Vaccination rates in patients with comorbid conditions Immunisation rates against pneumococcus were higher among patients with certain comorbidities. Specifically, the vaccination coverage against pneumococcus in patients suffering from COPD was $43 \%(18 / 40)$, in patients with asthma it was $50 \%(4 / 8)$, in patients with heart disease it was $45 \%$ (35/78), and in patients with type 2 diabetes it was $44 \%(11 / 25)$. Only patients with heart disease were vaccinated at a significantly higher frequency compared with those without heart disease (45 vs. $18 \%$, OR $3.66,95 \% \mathrm{Cl}, 1.51-8.89, P=0.003)$. The vaccination coverage for influenza was $70 \%(28 / 40)$ in patients suffering from COPD, in patients with asthma it was $87.5 \%(7 / 8)$, in patients with heart disease it was 69\% (54/78), and in patients with type 2 diabetes it was $72 \%(18 / 25)$. Only patients with underlying heart disease were vaccinated at a significantly higher frequency compared with those without heart disease (69\% vs. $48 \%$, OR $2.46,95 \% \mathrm{Cl}$, $1.15-5.28, P=0.019$ )

\section{Hospitalised and outpatient features}

Hospitalised patients were significantly older compared with outpatients (OR 1.05, 95\% Cl, 1.01-1.08, $P=0.025$ ), with more pack-years of smoking (OR $3.43,95 \% \mathrm{Cl}, 1.44-8.12, P=0.015$ for 40 or more pack-years of smoking). COPD was the only comorbidity that differed in favour of hospitalised patients (OR 6.28, 95\% Cl, 2.73-14.48, $P<0.0001)$. Asthma, heart disease, and type 2 diabetes were more frequently observed among hospitalised patients compared with outpatients, but none of the above differences were found to be statistically significant. Hospitalised patients reported multimorbidity at a significantly higher proportion compared with outpatients (OR 4.57, 95\% Cl, 2.03-10.30, $P<0.0001)$.

As regards patients' clinical measurements, respiratory rate, and white blood cell in the peripheral blood had significantly higher values in the hospitalised group (OR 1.02, 95\% Cl, 1.06-1.25 and OR $1.33,95 \% \mathrm{Cl}, 1.29-2.37, P<0.0001$ for respiratory rate and white blood cell, respectively), whereas $\mathrm{O}_{2}$ saturation and haemoglobin concentration were significantly lower (OR 0.82 , $95 \% \mathrm{Cl}, 0.73-0.92, P<0.0001$ for $\mathrm{O}_{2}$ saturation and OR $0.70,95 \%$ $\mathrm{Cl}, 0.54-0.91, P=0.001$ for haemoglobin). The CRB-65 score was more frequently available in hospitalised patients (92.5\%)

Table 1. General characteristics of recorded CAP patients

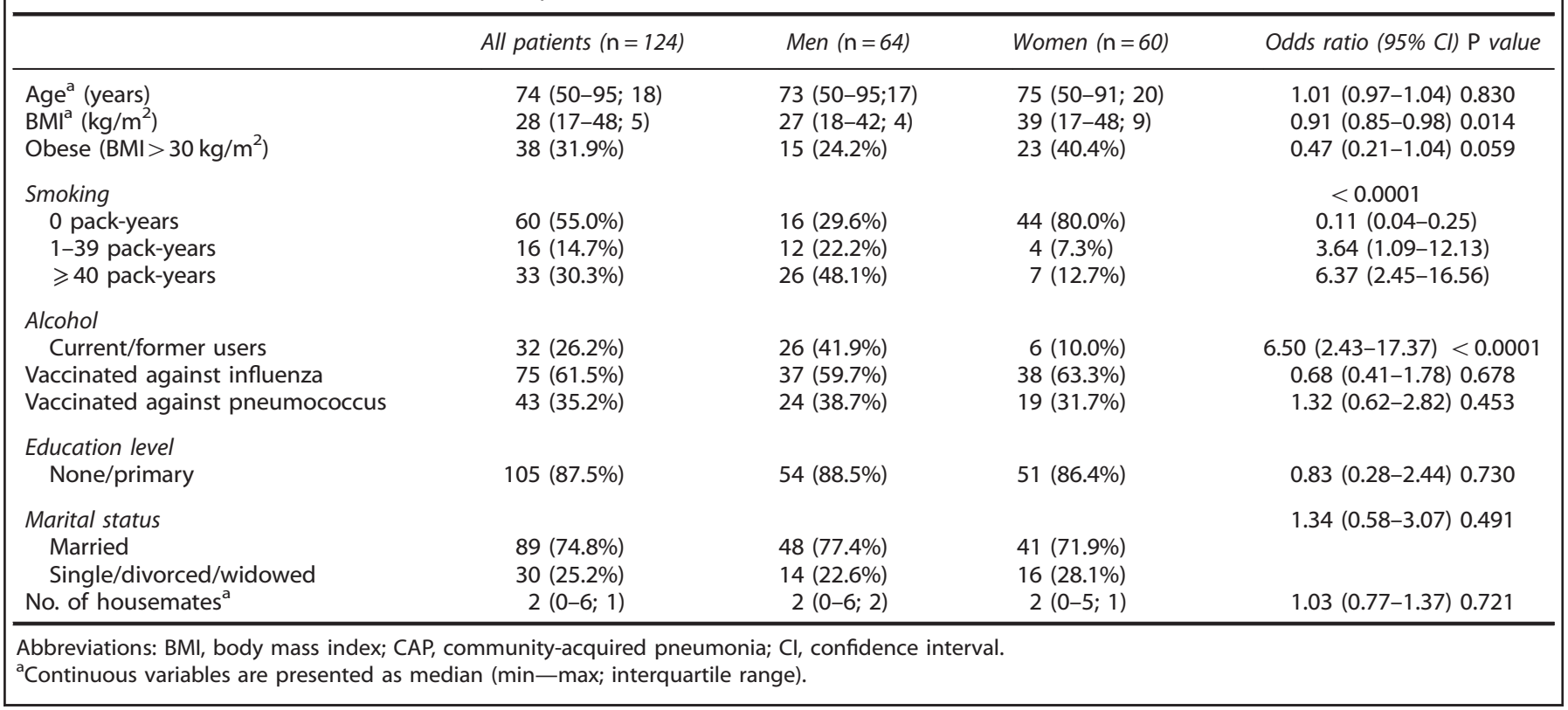


Table 2. Frequencies of common chronic illnesses of recorded CAP patients

\begin{tabular}{|c|c|c|c|c|}
\hline & All patients $(\mathrm{n}=124)$ & Men $(n=64)$ & Women $(n=60)$ & Odds ratio $(95 \% \mathrm{Cl}) \mathrm{P}$ value \\
\hline COPD & $40(32.5 \%)$ & $29(46.0 \%)$ & $11(18.3 \%)$ & $3.80(1.67-8.60) 0.001$ \\
\hline Asthma & $8(6.5 \%)$ & 1 (1.6\%) & 7 (11.9\%) & $0.12(0.01-0.99) 0.022^{\mathrm{a}}$ \\
\hline Heart disease & $80(64.5 \%)$ & 37 (57.8\%) & $43(71.7 \%)$ & $0.54(0.26-1.15) 0.107$ \\
\hline Type 2 diabetes & $26(21.0 \%)$ & $11(17.2 \%)$ & $15(25.0 \%)$ & $0.62(0.26-1.49) 0.286$ \\
\hline Immunosuppressive & $4(3.3 \%)$ & $1(1.6 \%)$ & $3(5.1 \%)$ & $0.30(0.03-2.98) 0.353$ \\
\hline Malignancy & $7(5.6 \%)$ & $3(4.7 \%)$ & $4(6.7 \%)$ & $0.69(0.15-3.21) 0.711$ \\
\hline Multimorbidity & 52 (43.3\%) & $28(45.2 \%)$ & $24(41.4 \%)$ & $1.17(0.57-2.41) 0.676$ \\
\hline
\end{tabular}

Odds ratio using women as the reference category.

Abbreviations: CAP, community-acquired pneumonia; $\mathrm{Cl}$, confidence interval; COPD, chronic obstructive pulmonary disease.

aFisher's exact test.

Table 3. Univariate analyses of factors between hospitalised patients and outpatients

\begin{tabular}{|c|c|c|c|}
\hline & Hospitalised $(n=40)$ & Outpatients $(\mathrm{n}=84)$ & Odds ratio $(95 \% \mathrm{Cl}) \mathrm{P}$ value \\
\hline $\operatorname{Age}^{a}$ & $78(53-94 ; 10)$ & $69(50-95 ; 21)$ & $1.05(1.01-1.08) 0.025$ \\
\hline Male gender & $22(55.0 \%)$ & $42(50.0 \%)$ & $0.60(0.57-2.60) 0.602$ \\
\hline $\mathrm{BMI}^{\mathrm{a}}\left(\mathrm{kg} / \mathrm{m}^{2}\right)$ & $28.6(20.0-41.8 ; 5.5)$ & $27.6(17.1-47.6 ; 5.6)$ & $1.02(0.95-1.09) 0.397$ \\
\hline Obese $\left(\mathrm{BMI}>30 \mathrm{~kg} / \mathrm{m}^{2}\right)$ & $15(37.5 \%)$ & $23(29.1 \%)$ & $1.46(0.65-3.26) 0.354$ \\
\hline Smoking & & & 0.015 \\
\hline 0 pack-years & $15(42.9 \%)$ & $45(60.8 \%)$ & $0.48(0.21-1.09)$ \\
\hline 1-39 pack-years & $3(8.6 \%)$ & $13(17.6 \%)$ & $0.40(0.11-1.51)$ \\
\hline$\geqslant 40$ pack-years & $17(48.6 \%)$ & $16(21.6 \%)$ & $3.43(1.44-8.12)$ \\
\hline Alcohol & & & $0.78(0.32-1.90) 0.578$ \\
\hline Current/former users & $9(23.1 \%)$ & $23(27.7 \%)$ & \\
\hline Vaccinated against influenza & 25 (64.1\%) & $50(60.2 \%)$ & $1.18(0.54-2.59) 0.680$ \\
\hline Vaccinated against pneumococcus & $11(28.2 \%)$ & 32 (38.6\%) & $0.63(0.27-1.43) 0.264$ \\
\hline COPD & $24(60.0 \%)$ & $16(19.3 \%)$ & $6.28(2.73-14.48)<0.0001$ \\
\hline Asthma & $5(12.5 \%)$ & $3(3.7 \%)$ & $3.76(0.85-16.62) 0.064$ \\
\hline Heart disease & $30(75.0 \%)$ & 50 (59.5\%) & $2.04(0.88-4.72) 0.092$ \\
\hline Type 2 diabetes & $10(25.0 \%)$ & $16(19.0 \%)$ & $1.42(0.58-3.48) 0.447$ \\
\hline Immunosuppressed & $3(7.5 \%)$ & $1(1.2 \%)$ & $6.57(0.66-65.26) 0.103$ \\
\hline Malignancy & $2(5.0 \%)$ & $5(6.0 \%)$ & $0.83(0.15-4.48) 0.830$ \\
\hline Multimorbidity & 27 (67.5\%) & 25 (31.2\%) & $4.57(2.03-10.30)<0.0001$ \\
\hline $\mathrm{SBP}^{\mathrm{a}}$ & $130(104-191 ; 25)$ & $134(105-180 ; 16)$ & $0.99(0.97-1.02) 0.449$ \\
\hline $\mathrm{DBP}^{\mathrm{a}}$ & $76(55-128 ; 15)$ & $80(50-120 ; 10)$ & $1.00(0.97-1.04) 0.524$ \\
\hline Respiratory rate (b.p.m.) $^{a}$ & $24(14-36 ; 8)$ & $17(10-39 ; 7)$ & $1.02(1.06-1.25)<0.0001$ \\
\hline $\mathrm{O}_{2}$ Saturation $^{\mathrm{a}}(\%)$ & $92(72-97 ; 6)$ & $94(78-99 ; 3)$ & $0.82(0.73-0.92)<0.0001$ \\
\hline $\mathrm{Hb}^{\mathrm{a}}(\mathrm{mg} / \mathrm{dl})$ & $11.9(9.1-16.0 ; 3.0)$ & $13.3(5.7-18.1 ; 1.8)$ & $0.70(0.54-0.91) 0.001$ \\
\hline$W_{B C}^{a}(m g / d l)$ & $10,550(5,900-35,000 ; 7,650)$ & $9,550(3,700-18,100 ; 5,975)$ & $1.33(1.29-2.37) 0.032$ \\
\hline Sleep hyperhidrosis & $2(5.3 \%)$ & $42(50.0 \%)$ & $0.06(0.01-0.25)<0.0001$ \\
\hline Confusion & $5(12.8 \%)$ & $2(2.4 \%)$ & $6.03(1.12-32.60) 0.032$ \\
\hline Chest pain & 7 (17.9\%) & $35(41.7 \%)$ & $0.31(0.12-0.77) 0.01$ \\
\hline Abnormal respiratory sounds & $36(94.7 \%)$ & $68(81.0 \%)$ & $4.24(0.92-19.45) 0.047$ \\
\hline CRB-65 score & & & $2.21(0.68-7.22) 0.184$ \\
\hline 0 & 5 (13.5\%) & $10(25.6 \%)$ & \\
\hline$\geqslant 1$ & $32(86.5 \%)$ & $29(74.4 \%)$ & \\
\hline
\end{tabular}

Odds ratios are computed using outpatients as the reference category. Odds ratios for continuous variables refer to a unit increase in each value except WBC, where they refer to one thousand units increase in its value.

Abbreviations: $\mathrm{BMI}$, body mass index; $\mathrm{CAP}$, community-acquired pneumonia; $\mathrm{Cl}$, confidence interval; $\mathrm{COPD}$, chronic obstructive pulmonary disease; CRB-65, C:confusion, R:respiratory rate, B:blood pressure at 65 years of age and older; DBP, diastolic blood pressure; Hb, haemoglobin; SBP, systolic blood pressure; WBC, white blood cell.

${ }^{a}$ Continuous variables are presented as median ( $\min -\max$; interquartile range).

compared with $39 / 84$ in outpatients (46.4\%). The majority of patients presented CRB-65 scores $\geqslant 1$, with 10 outpatients (25.6\%) and 5 inpatients (13.5\%) presenting CRB-65 score $=0$. More details are depicted in Table 3.

Determinants for hospitalisation in CAP patients

Multivariate logistic regression was performed to identify independent predictors associated with hospitalisation due to
CAP. Significant determinants were advanced age $(\geqslant 74$ years, OR 7.1, 95\% Cl, 2.23-22.79, $P=0.001)$, underlying obesity $\left(\mathrm{BMl}>30 \mathrm{~kg} / \mathrm{m}^{2}\right.$, OR 3.4, 95\% Cl, $1.08-10.52, \quad P=0.037$, smoking ( $\geqslant 40$ pack-years, OR $3.8,95 \% \mathrm{Cl}, 1.81-18.42, P=0.040$ ), underlying multimorbidity (OR $5.8,95 \% \mathrm{Cl}, 1.81-18.42, P=0.003)$, and pneumococcal vaccination $(\mathrm{OR} 0.29,95 \% \mathrm{Cl}, 0.09-0.95$, $P=0.041$ ). Details of the regression model are presented in Table 4. 
Length of hospitalisation

The median duration of hospitalisation was 7 days and was significantly higher for women compared with men $(P=0.032)$, in the winter season $(P=0.001)$, when malignancy was present $(P<0.027)$ and when arterial oxygen concentration was less or equal to $58.8 \mathrm{mg} / \mathrm{dl}(P=0.040)$. There was also a trend for increased duration of hospitalisation when tachypnoea was present at the time of the first examination $(P=0.051)$. No significant variation in the duration of hospitalisation was observed upon comparisons with regard to patients' age, different BMI groups, or chronic conditions (heart disease, COPD, type 2 diabetes, and asthma) (data not shown). Results are presented in Table 5.

Table 4. Logistic regression predicting the odds of hospitalisation due to CAP ( $n=104$ cases included in the analysis)

\begin{tabular}{lccc}
\hline Determinant & Odds ratio & $95 \% \mathrm{Cl}$ & $\mathrm{P}$ value \\
\hline Age $\geqslant 74$ years & 7.13 & $2.23-22.79$ & 0.001 \\
Obese & 3.36 & $1.08-10.52$ & 0.037 \\
0 Pack-years & 1.00 (reference) & & 0.019 \\
$1-39$ Pack-years of smoking & 0.317 & $0.06-1.73$ & 0.185 \\
$\geqslant 40$ Pack-years of smoking & 3.817 & $1.07-13.68$ & 0.040 \\
Multimorbidity & 5.77 & $1.81-18.42$ & 0.003 \\
Vaccinated against & 0.29 & $0.09-0.95$ & 0.041 \\
pneumococcus & & & \\
\hline$X^{2}$-test 36.639 on d.f. 6; $P$ value $<0.0001 ;$ pseudo- $R^{2}=0.412$. & \\
$95 \%$ Cl, 95\% confidence interval, Hosmer and Lemeshow $X^{2}$-test $6.39 ;$ \\
$P=0.604$. \\
Abbreviations: CAP, community-acquired pneumonia; Cl, confidence \\
interval.
\end{tabular}

Table 5. Duration of hospitalisation

\begin{tabular}{|c|c|c|}
\hline & Days in hospital ${ }^{a}$ & $\mathrm{P}$ value \\
\hline Gender & & 0.032 \\
\hline Male & $6.5(2-20 ; 6)$ & \\
\hline Female & $8.0(4-16 ; 7)$ & \\
\hline Season of CAP occurrence & & 0.001 \\
\hline Winter & $12(7-20 ; 6)$ & \\
\hline Other & $7(2-16 ; 4)$ & \\
\hline Malignancy & & 0.027 \\
\hline Yes & $17(14-20 ; 6)$ & \\
\hline No & $7(2-16 ; 6)$ & \\
\hline Asthma & & 0.089 \\
\hline Yes & $8(7-16 ; 7)$ & \\
\hline No & $7(2-20 ; 6)$ & \\
\hline Dyspnoea & & 0.067 \\
\hline Yes & $7.5(3-20 ; 6)$ & \\
\hline No & $5(2-8 ; 5)$ & \\
\hline Tachypnoea & & 0.051 \\
\hline Yes & $7(3-20 ; 6)$ & \\
\hline No & $4(2-7 ; 5)$ & \\
\hline Lung-percussion & & 0.081 \\
\hline Abnormal & $8(4-16 ; 5)$ & \\
\hline Normal & $7(2-20 ; 6)$ & \\
\hline $\mathrm{PaO}_{2}(\mathrm{mg} / \mathrm{dl})$ & & 0.040 \\
\hline$\leqslant 58.8$ & $8(4-16 ; 5)$ & \\
\hline$>58.8$ & $6(2-20 ; 4)$ & \\
\hline \multicolumn{3}{|c|}{$\begin{array}{l}\text { Abbreviation: CAP, community-acquired pneumonia. } \\
\text { aContinuous variables are presented as median (min-max; interquartile } \\
\text { range). }\end{array}$} \\
\hline
\end{tabular}

\section{DISCUSSION}

Main findings

This study highlighted certain key issues regarding various aspects of CAP in adults within the context of PHC. The hospitalisation rate was $32 \%$, with a median duration of 7 days and an overall mortality of less than $2 \%$ all within hospital. With regard to patient characteristics, about one-third of patients were obese and almost half were current or former smokers. Forty-two percent of CAP patients reported multimorbidity, with the most frequent chronic conditions being heart diseases followed by COPD and type 2 diabetes. Approximately one-third of patients were vaccinated against pneumococcus, with the 23-valent polysaccharide vaccine, and almost two-thirds were vaccinated against influenza. Advanced age, obesity, underlying multimorbidity, and smoking independently increased the odds for hospitalisation due to CAP, whereas pneumococcal vaccination decreased the respective odds.

Interpretation of findings in relation to previously published work CAP incidence. The annual age-standardised CAP incidence in the present study was found to be 236.7 cases per 100,000 persons aged 50 years or above. A similar annual CAP incidence of 233 per 100,000 persons was also reported by a study conducted in the United Kingdom. ${ }^{22}$ Both our study and the UK study were conducted within the primary care context and are among the few studies to have explored CAP incidence in primary care in Europe.

This study did not include information about the causal agents of CAP as no blood cultures were performed to identify the pathogens as in other recent studies. ${ }^{23}$ Despite the fact that the identification of CAP causality was not the focus of the present study, urine samples were collected from all 124 patients. All samples were stored at a temperature of $-20^{\circ} \mathrm{C}$ and subsequently sent for analysis at the Pfizer laboratories in New York. Using the Luminex Urinary Antigen Detection method, six cases of S. pneumoniae (5\%) were identified. The most prevalent serotype was Pn 19A (three cases) followed by Pn 23F, Pn 3, and Pn 7F (one case for each serotype).

Findings related to patient characteristics. No significant gender differences were found. Our results were similar to other studies that showed equal CAP male to female ratios ${ }^{24,25}$ and contrary to another primary care study where women were disproportionately diagnosed with pneumonia. ${ }^{19}$ Significant differences were observed in our study in terms of alcohol and smoking, indicating a male predominance. This may be explained by the fact that our sample was mainly rural where these 'habits' are considered mainly a male 'activity' (personal observations of the authors who serve these rural areas). In our study, the rate of those who were current/former smokers was 45\% (70\% in men and $20 \%$ in women) and was higher particularly in men compared with another Greek study ${ }^{26}$ where the prevalence of smoking was estimated at $41 \%$ ( $45 \%$ in men, $38 \%$ in women). The majority of patients were classified as either overweight or obese. This finding was expected, as a recent primary care study regarding new cases of anaemia that was conducted in a similar setting in rural Crete found that $77 \%$ of participants were overweight or obese as well. ${ }^{27}$

Research previously conducted in Greece has already reported the most common diagnoses made in the primary care setting. ${ }^{28,29}$ These diagnoses were used as a guide to record chronic illnesses in our study. About two-thirds of patients reported suffering from cardiovascular diseases, one-third from COPD and $21 \%$ from type 2 diabetes. COPD frequency was significantly higher in men compared with women and an explanation can be owing to the fact that men were smokers at a much higher extent compared with women. Moreover, this is in accordance with the only study that examined COPD prevalence 
at the national level in Greece, including rural areas, and found a male gender-standardised prevalence of $11.6 \%$, whereas for women it was $4.8 \% .^{30}$ The frequency of type 2 diabetes was almost $25 \%$ in women and $17 \%$ in men and can be explained by the increased BMl observed in women compared with men. Despite the within-gender variations, these major chronic conditions appear to be more frequent in the population of our study compared with other Greek studies. ${ }^{27,31,32}$ Nevertheless, our findings seem to be in accordance with the literature, which suggests that patients suffering from heart diseases, COPD, or type 2 diabetes are at a higher risk for CAP. ${ }^{19,33,34}$

Findings related to hospitalisations. Owing to the great discrepancies in the recognition and management of CAP, there is a need for primary care physicians to be able to recognise which cases should be referred to hospitals. ${ }^{35}$ For this reason, numerous severity scoring systems have been developed and proposed for use in primary care, such as the CURB-65 and the CRB- $65 .^{20,21}$ In the present study, the CRB-65 was used, as the only difference between the two tools was that the CURB-65 includes urea estimation, which is not always available in primary care practices. The CRB- 65 has been proved as a simple tool that can be used at a community level. ${ }^{36}$ Our study revealed that the majority of our patients with a low-risk CRB-65 score were managed at home. However, a significant percentage of patients with a low score were admitted to the hospital, raising concerns that primary care physicians may over-refer patients to the hospitals. The widely used primary care measurement of pulse oximetry has been shown to be useful when making a decision regarding hospitalisation, as there were significant differences in oxygen saturation levels between hospitalised patients and outpatients. Increasing hypoxaemia is associated with higher mortality and critical care admission even when adjusted for CRB-65; therefore, its use should be recommended. ${ }^{37,38}$

In our study population, about one-third of CAP patients required inpatient hospitalisation. This rate seems within the boundaries reported in the literature, yet somewhat higher from that reported in a large retrospective study of patients aged $\geqslant 50$ years conducted in the United States. ${ }^{39}$ Results of this study with regard to hospitalisation determinants adds to the discussion regarding the necessity of pneumococcal vaccination, indicating that vaccinated patients presented lower odds for hospitalisation compared with nonvaccinated patients. In addition, advanced age and underlying multimorbidity independently increased the odds for patient hospitalisation similarly to other studies that showed increased incidence, burden and mortality as age and multimorbidity increased. ${ }^{25,39,40}$ Primary care physicians should take age and multimorbidity into account when managing CAP patients, as older age and multimorbidities correlate with a higher mortality. ${ }^{25}$ Obese patients in our study also presented higher odds for hospitalisation compared with nonobese patients, in parallel with findings of studies dealing with $\mathrm{H} 1 \mathrm{~N} 1$ influenza that reported higher hospitalisation rates among obese patients. ${ }^{41-44}$ Besides these, pack-years independently of chronic conditions increased the odds for hospitalisation similarly to other studies that showed a strong correlation of pack-years with invasive pneumococcal disease. ${ }^{45,46}$

Findings related to CAP patients' immunisation status. About onethird of CAP patients were vaccinated against pneumococcus and two-thirds against influenza. Although the rate of vaccination against pneumococcus was significantly higher in patients with underlying heart disease, this was not the case for patients with underlying COPD, asthma, or type 2 diabetes. Overall, the level of vaccination coverage against pneumococcus was found to be somewhat low given the fact that the majority of patients were at a high risk for pneumococcal disease either owing to age or comorbidities. This is in accordance with the 2010 International Primary Care Respiratory Group research needs statement that highlighted the need of finding effective strategies to improve uptake rated for vaccination. ${ }^{17}$ The rate of vaccination against influenza was relatively high in CAP patients suffering from certain chronic illnesses such as COPD, asthma, or type 2 diabetes. CAP patients suffering from heart disease were vaccinated at a significantly higher proportion compared with CAP patients without underlying heart disease.

\section{Strengths and limitations}

This study is subjected to the limitations of any observational study. As a result, an overall underestimation in the number of reported CAP cases that affected the general estimation of CAP incidence in our setting is possible, as a gate-keeping system is not established in the Greek Health Care system. In an effort to diminish this effect, a capture-re-capture study was conducted that estimated a prevalence of CAP as 296.5 cases per 100,000 persons. On the basis of this approach, a total of 59.8 CAP cases per 100,000 persons were possibly not captured either because they were hospitalised in private clinics or received medical care outside of the primary or secondary health-care resources that participated in the study. As our primary focus was to measure the burden of CAP in primary care, this study did not use a control group, and thus it missed the chance of discussing current findings with a comparative view. Finally, the study period was of 1 year; therefore, conclusions could be considered safe in terms of seasonal variation. ${ }^{47}$ Despite these limitations, this study, to our knowledge, is the first primary care-based observational study that reports the real burden of CAP in the PHC services.

Implications for future research, policy, and practice

This study has highlighted several aspects regarding the burden and epidemiology of CAP in the context of a rural PHC setting in southern Europe, where limited data have been published until now. This study could also add to the ongoing literature discussion regarding the effectiveness of pneumococcal vaccination in older adults. The findings could contribute to the formation of guidelines regarding CAP prevention and timely treatment of at-risk patients within primary care settings.

\section{CONCLUSIONS}

This observational study that was conducted in rural primary care services succeeded in recording the majority of CAP cases and highlighted certain determinants regarding patients' hospitalisation. Certain outcomes of the study could serve the primary care reform that is currently under discussion in Greece during the austerity period.

\section{ACKNOWLEDGEMENTS}

The authors thank Associate Professor of Epidemiology Nikolaos Tzanakis and the PhD candidate Dimitra Sifaki-Pistolla for their contribution to the design of the Capture-Re-Capture study. The Cretan Cap Research Group: from the Health Centre of Ano Viannos the following primary care practitioners: loanna Stefanaki, Voula Dimou Akrivi, Charalampos Mylonakis, and Emmanouil Kondylakis; from the Health Centre of Charakas the following primary care practitioners: Vaso Lemonomichelaki, Georgios Mathioudakis, Zoi Troulaki, Despoina Chatzisymeon, and Dimitrios Mprimis; from the Health Centre of Kastelli the following primary care physicians: Nikolaos Tsakountakis, Rodanthi Pateli, Kornilia Makri, Aggeliki Vasilaki, Eirini Kalogridaki, Nikolaos Ploumis, and Charalampos Apostolakis; from the Health Centre of Aghia Varvara the following primary care physicians: Theodoros Vasilopoulos, and Stavros Vlassiadis; from the Health Centre of Moires the following primary care physicians: Georgios Ktistakis, loannis Platakis, Maria Panieraki, and Eleftheria Zervaki; from the Health Centre of Arkalochori the following primary care physicians: Polyvios Papadokostakis, Ifigeneia Mpoutierou, Evangelia Georgoulaki, and Polydoros Kallergis; from the Venizeleio-Pananeio Hospital, the pulmonologist Nikolaos 
Bachlitzanakis (director of the pulmonology clinic); from the University Hospital of Heraklion hospital, the pulmonologists Eirini Lampiri and Sevasti Koumiotaki.

\section{CONTRIBUTIONS}

$A B$ participated in the study, performed data entry and analyses, was the main author of the article, and drafted the manuscript. GD participated in the study as coordinator and reviewed the manuscript. IT participated in the study, was a co-author of the article, and reviewed the manuscript. NS conceived and supervised the study, was a co-author of the article, and reviewed the manuscript. All authors have approved the final manuscript. CL conceived and supervised the study, was a co-author of the article, and reviewed the final version of the manuscript

\section{COMPETING INTERESTS}

IT is an Associate editor of npj Primary Care Respiratory Medicine, but was not involved in the editorial review of, nor the decision to publish, this article. All other authors declare no conflict of interest.

\section{FUNDING}

This study was supported by an unrestricted grant from Pfizer Inc. The established standards were strictly followed with the University of Crete's Special Account for Research (ELKE).

\section{REFERENCES}

1 File TM. Community-acquired pneumonia. Lancet 2003; 362: 1991-2001.

2 Longo DL, Fauci AS, Kasper DL, Hauser SL, Jameson JL, Loscalzo J (eds) Harrison's Principles of Internal Medicine18th edn.McGraw Hill: New York, 2011.

3 Leeper KV Jr. Severe community-acquired pneumonia. Semin Respir Infect 1996; 11: 96-108.

4 Murphy SL. Deaths: final data for 1998. Natl Vital Stat Rep 2000; 48: 1-105.

5 Almirall J, Bolibar I, Vidal J, Sauca G, Coll P, Niklasson B et al. Epidemiology of community-acquired pneumonia in adults: a population-based study. Eur Respir $J$ 2000; 15: 757-763.

6 Fine MJ. Solutions for difficult diagnostic cases of community-acquired pneumonia. Chemotherapy 2001; 47(Suppl 4): 3-10, discussion 26-7.

7 Marrie TJ, Huang JQ. Epidemiology of community-acquired pneumonia in Edmonton, Alberta: an emergency department-based study. Can Respir J 2005; 12 $139-142$.

8 Woodhead MA, Macfarlane JT, McCracken JS, Rose DH, Finch RG. Prospective study of the aetiology and outcome of pneumonia in the community. Lancet 1987; 1: 671-674.

9 Almirall J, Morato I, Riera F, Verdaguer A, Priu R, Coll P et al. Incidence of community-acquired pneumonia and Chlamydia pneumoniae infection: a prospective multicentre study. Eur Respir J 1993; 6: 14-18.

10 Jokinen $\mathrm{C}$, Heiskanen L, Juvonen $\mathrm{H}$, Kallinen S, Karkola K, Korppi M et al. Incidence of community-acquired pneumonia in the population of four municipalities in Eastern Finland. Am J Epidemiol 1993; 137: 977-988.

11 Fine MJ, Auble TE, Yealy DM, Hanusa BH, Weissfeld LA, Singer DE et al. A prediction rule to identify low-risk patients with community-acquired pneumonia. $N$ Engl J Med 1997; 336: 243-250.

12 Fine MJ, Smith MA, Carson CA, Mutha SS, Sankey SS, Weissfeld LA et al. Prognosis and outcomes of patients with community-acquired pneumonia: a meta-analysis. JAMA 1996; 275: 134-141.

13 Niederman MS, McCombs JS, Unger AN, Kumar A, Popovian R. The cost of treating community-acquired pneumonia. Clin Ther 1998; 20: 820-837.

14 Bartlett J, Dowell SF, Mandell LA, File TM Jr, Musher DM, Fine MJ. Guidelines from the Infectious Diseases Society of America: practice guidelines for the management of community-acquired pneumonia. Clin Infect Dis 2000; 31: 347-382.

15 Vernet G, Saha S, Satzke C, Burgess DH, Alderson M, Maisonneuve JF et al. Laboratory-based diagnosis of pneumococcal pneumonia: state of the art and unmet needs. Clin Microbiol Infect 2011; 17(Suppl 3): 1-13.

16 Levy ML. Guideline-defined asthma control: a challenge for primary care. Eur Respir J 2008; 31: 229-231.

17 Pinnock H, Thomas M, Tsiligianni I, Lisspers k, Østrem A, Ställberg B et al. The International Primary Care Respiratory Group (IPCRG) Research Needs Statement 2010. Prim Care Respir J 2010; 19(Suppl 1): S1-S20.
18 Levy ML, Le Jeune I, Woodhead MA, Macfarlaned JT, Lim WS, British Thoracic Society Community Acquired Pneumonia in Adults Guideline Group. Primary care summary of the British Thoracic Society Guidelines for the management of community acquired pneumonia in adults: 2009 update. Prim Care Respir J 2010; 19: 21-27.

19 Evertsen J, Baumgardner DJ, Regnery A, Banerjee I. Diagnosis and management of pneumonia and bronchitis in outpatient primary care practices. Prim Care Respir J 2010; 19: 237-241.

20 Lim WS, Lewis S, Macfarlane JT. Severity prediction rules in community acquired pneumonia: a validation study. Thorax 2000; 55: 219-223.

21 Lim WS, van der Eerden MM, Laing R, Boersma WG, Karalus N, Town Gl et al. Defining community acquired pneumonia severity on presentation to hospital: an international derivation and validation study. Thorax 2003; 58: 377-382.

22 Myles PR, McKeever TM, Pogson Z, Smith CJ, Hubbard RB. The incidence of pneumonia using data from a computerized general practice database. Epidemiol Infect 2009; 137: 709-716.

23 Sherwin RL, Gray S, Alexander R, McGovern PC, Graepel J, Pride MW et al. Distribution of 13-valent pneumococcal conjugate vaccine Streptococcus pneumoniae serotypes in US adults aged $\geqslant 50$ years with community-acquired pneumonia. J Infect Dis 2013; 208: 1813-1820.

24 Haegstad LK, Bjotveit T, Johannessen A, Gulsvik A. How frequently are physiological variables recorded in the emergency room in patients with obstructive pulmonary diseases and pneumonia? Prim Care Respir J 2009; 18: 95-99.

25 Mbata GC, Chukwuka CJ, Onyedum CC, Onwubere BJ. The CURB-65 scoring system in severity assessment of Eastern Nigerian patients with community-acquired pneumonia: a prospective observational study. Prim Care Respir J 2013; 22: 175-180.

26 Filippidis FT, Vardavas $\mathrm{Cl}$, Loukopoulou A, Behrakis P, Connolly GN, Tountas Y. Prevalence and determinants of tobacco use among adults in Greece: 4 year trends. Eur J Public Health 2013; 23: 772-776.

27 Lionis C, Symvoulakis E, Duijker G, Anastasiou F, Dimitrakopoulos S, Kladou C et al. Reporting new cases of anaemia in primary care settings in Crete, Greece: a rural practice study. Asia Pac Fam Med 2012; 11: 4.

28 Mariolis A, Merkouris B, Lionic C. Introducing general practice in urban Greece: focus on morbidity profile. Eur J Gen Pract 2004; 10: 105-106.

29 Koutis AD, Isacsson A, Lionis CD, Lindholm LH, Svenninger K, Fioretos M. Differences in the diagnose panorama in primary health care in Dalby, Sweden and Spili, Crete. Scand J Soc Med 1993; 21: 51-58.

30 Tzanakis N, Anagnostopoulou U, Filaditaki V, Christaki P, Siafakas N, COPD group of the Hellenic Thoracic Society. Prevalence of COPD in Greece. Chest 2004; 125: 892-900.

31 Minas M, Koukosias N, Zintzaras E, Kostikas K, Gourgoulianis KI. Prevalence of chronic diseases and morbidity in primary health care in central Greece: an epidemiological study. BMC Health Serv Res 2010; 10: 252

32 Panagiotakos DB, Pitsavos C, Chrysohoou C, Skoumas I, Stefanadis C. Prevalence and five-year incidence (2001-2006) of cardiovascular disease risk factors in a Greek sample: the ATTICA Study. Hellenic J Cardiol 2009; 50: 388-395.

33 Almirall J, Bolíbar I, Balanzó X, González CA. Risk factors for community-acquired pneumonia in adults: a population-based case-control study. Eur Respir J 1999; 13: 349-355.

34 Koivula I, Sten M, Mäkelä PH. Risk factors for pneumonia in the elderly. Am J Med 1994; 96: 313-320.

35 Fine MJ, Smith MA, Carson CA, Mutha SS, Sankey SS, Weissfeld LA et al. Prognosis and outcomes of patients with community-acquired pneumonia. A meta-analysis. JAMA 1996; 275: 134-141.

36 Capelastegui A, España PP, Quintana JM, Areitio I, Gorordo I, Egurrola M et al. Validation of a predictive rule for the management of community-acquired pneumonia. Eur Respir J 2006; 27: 151-157.

37 Bewick T, Greenwood S, Lim WS. What is the role of pulse oximetry in the assessment of patients with community-acquired pneumonia in primary care? Prim Care Respir J 2010; 19: 378-382.

38 Levin KP, Hanusa BH, Rotondi A, Singer DE, Coley CM, Marrie TJ et al. Arterial blood gas and pulse oximetry in initial management of patients with communityacquired pneumonia. J Gen Intern Med 2001; 16: 590-598.

39 Kaplan V, Angus DC, Griffin MF, Clermont G, Watson RS, Linde-Zwirble WT. Hospitalized community-acquired pneumonia in the elderly: age- and sex-related patterns of care and outcome in the United States. Am J Respir Crit Care Med 2002; 165: 766-772.

40 Ochoa-Gondar O, Vila-Córcoles A, de Diego C, Arija V, Maxenchs M, Grive M et al. EVAN-65 Study Group. The burden of community-acquired pneumonia in the elderly: the Spanish EVAN-65 study. BMC Public Health 2008; 8: 222.

41 Barrau M, Larrieu S, Cassadou S, Chappert JL, Dussart P, Najioullah F et al. Hospitalized cases of influenza $\mathrm{A}(\mathrm{H} 1 \mathrm{~N} 1)$ pdm09 in the French territories of the Americas, July 2009-March 2010. Rev Panam Salud Publica 2012; 32: 124-130. 
42 Rodríguez-Baño J, Paño-Pardo JR, Múñez Rubio E, Segura Porta F. Pregnancy obesity and other risk factors for complications in influenza $A(H 1 N 1)$ pdm09 infection. Enferm Infecc Microbiol Clin 2012; 30: 32-37.

43 Gutiérrez-Pizarraya A, Pérez-Romero P, Alvarez R, Aydillo TA, Osorio-Gómez G, Milara-lbáñez $C$ et al. Unexpected severity of cases of influenza $B$ infection in patients that required hospitalization during the first postpandemic wave. J Infect 2012; 65: 423-430.

44 Jiménez-García R, Hernández-Barrera V, Rodríguez-Rieiro C, Lopez de Andres A de Miguel-Diez J, Jimenez-Trujillo I et al. Hospitalizations from pandemic Influenza [A(H1N1)pdm09] infections among type 1 and 2 diabetes patients in Spain. Influenza Other Respir Viruses 2013; 7: 439-447.

45 Baik I, Curhan GC, Rimm EB, Bendich A, Willett WC, Fawzi WW. A prospective study of age and lifestyle factors in relation to community-acquired pneumonia in US men and women. Arch Intern Med 2000; 160: 3082-3088.
46 Nuorti JP, Butler JC, Farley MM, Harrison LH, McGeer A, Kolczak MS et al. Cigarette smoking and invasive pneumococcal disease. Active Bacterial Core Surveillance Team. N Engl J Med 2000; 342: 681-689.

47 Lieberman D, Lieberman D, Porath A. Seasonal variation in community-acquired pneumonia. Eur Respir J 1996; 9: 2630-2634.

(1) $\Theta$ This work is licensed under a Creative Commons Attributioncc) NonCommercial-NoDerivatives 4.0 International License. The images or other third party material in this article are included in the article's Creative Commons license, unless indicated otherwise in the credit line; if the material is not included under the Creative Commons license, users will need to obtain permission from the license holder to reproduce the material. To view a copy of this license, visit http:// creativecommons.org/licenses/by-nc-nd/4.0/ 